

\section{Revolución cultural y orgía creativa: el Taller NN (1988-1991). Entrevista con Alfredo Márquez}

Miguel A. Lopez

Esta entrevista es un fragmento de una extensa conversación sostenida con el artista y comunicador visual Alfredo Márquez (n. 1963) en torno a algunas experiencias de producción estética y política forjadas durante los anos del conflicto armado en el Perú desde 1980. El presente dialogo focaliza una de las experiencias más intensas de radicalizacion teorica, experimentación estética y reinvención politica emergidas en los anos 80 , el Taller NN (1988-1991), pero ademas sus preludios y efectos diferidos, desde la perspectiva de uno de sus mas activos miembros.

La experiencia colectiva del Taller NN es inseparable de un proceso grupal anterior: el colectivo Bestiarios, un grupo de estudiantes de arquitectura que propician durante 1984 y 1987 encuentros multidisciplinarios donde el rock subterráneo, el teatro, la poesia, la arquitectura participativa y las artes visuales colisionan en un intento de renovar los modos de participación politica desde un vértice libertario, anárquico e informal. Durante aquellos años de guerra y crisis generalizada se produce una transformación radical de los lenguajes, excediendo y desestructurando el repertorio visual de las izquierdas tradicionales. Del mismo modo, reflexionar sobre la experiencia del Taller NN resulta indesligable de las represiones que sufrieron algunos de sus integrantes y de las secuelas y repliegues generacionales de aquella movida 'subte' contestataria en los primeros años de la dictadura de Alberto Fujimori en los 90 :

Este diálogo forma parte de un proyecto de reflexion en curso sobre las nuevas subjetividades y los renovados comportamientos politicos que. fuera de toda organicidad ortodoxa, tienen lugar en el Perú en los años 80 y 90 desde la producción cultural independiente. l.a conversación con Márquez focaliza algunas experiencias decisivas en aquellos anos para su trabajo colectivo, como la frustrada participación en la revista Morgenes, la producción de la Carpeta Negra (1988), el viaje a la Bienal de La Habana y la caida del muro de Berlín (1989), sus encuentros con los ex integrantes del grupo E.P.S. Huayco (1980-1981), con Fernando "Coco" Bedoya y con artistas de la escena de avanzada chilena. Pero tambien en torno a las afinidades con otros procesos que asumen la funcionalidad politica de la estética como la vanguardia soviética o la poesía de Vallejo. Durante sus breves años de existencia la producción gráfica del Taller NN fue una explicita reacción a las masacres y desapariciones ilegales en el pais, a través de usos corrosivos y desacralizantes de la iconografia comunista y el grito militante.

1 El debilitamiento y posternor disolución de aquella escona contracultural independiente a fines de los 80 e inxios de los 90 se acelerara en algunos casos como producto de su propio radicalismo, y en varios otros como resultado directo de la presion y volenca autoritaria eiercida contra ella. Todas las notas a pie en el texto son del autor. 


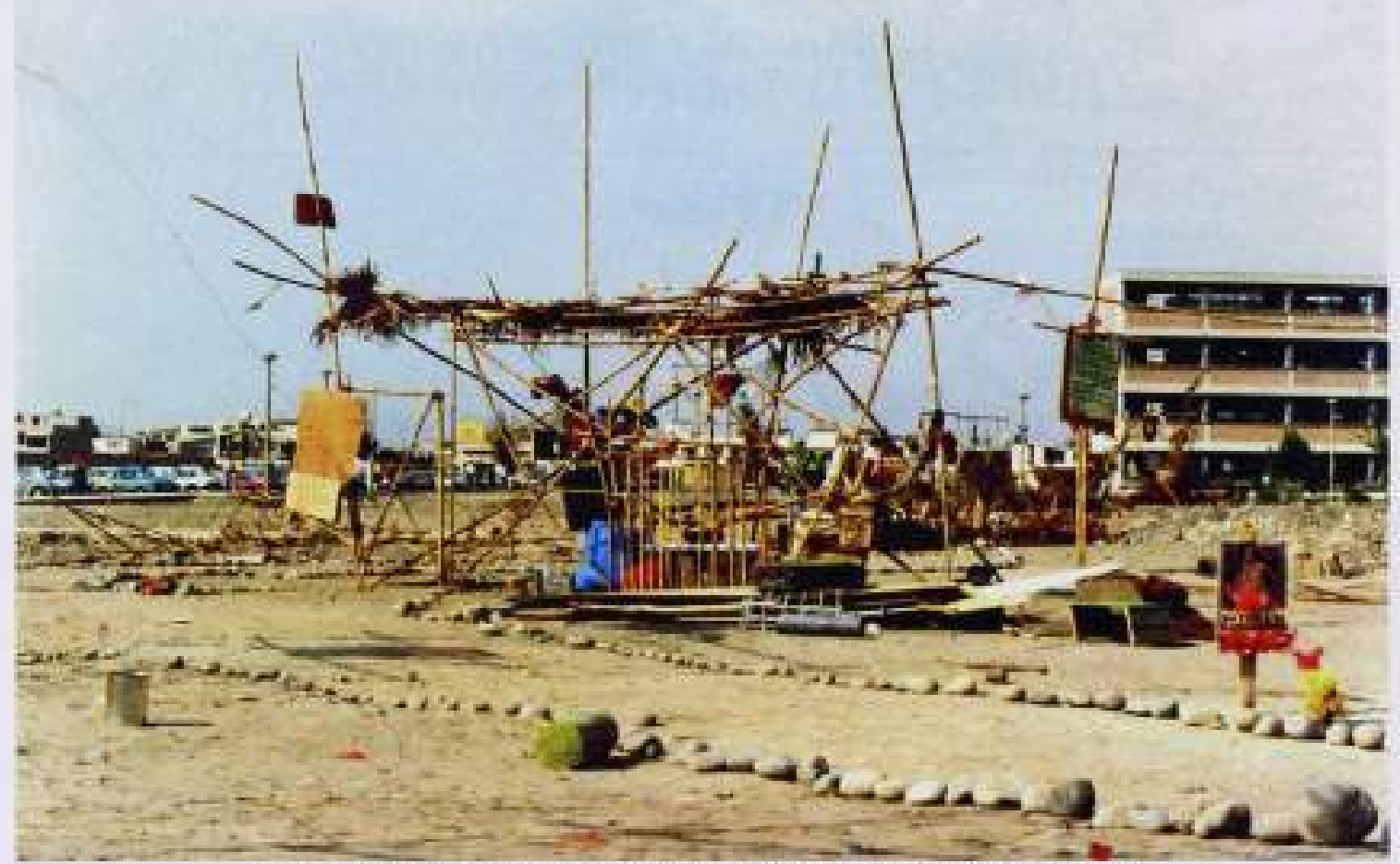

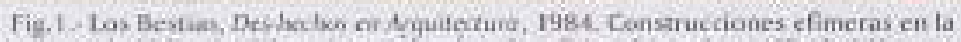

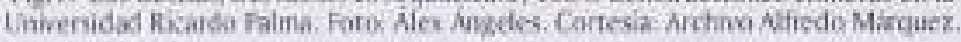

Los subtitulos de esta conversación han sido tomados del 'manifiesto' de NN-PERÚ (Carpeta Negra) (1988).

\section{"Bestiario y rocanrol" (El producto excedente)}

Miguel López: A mediados de los 80 varios de ustedes, entonces estudiantes de arquitectura de la Universidad Ricardo Polma, se encontraban agrupados en el colectivo Bestiarios organizando eventos de arquitectura efimera y festivales anarquistas multidisciplinarios, que logran aglamerar los gestos mas beligerantes y arriesgados de la liamada movida 'subte' que intersecto las vertientes más politizodas de la poesia, la musica y la visualidod.' Sur ruptura como grupo ocurre en 1987.

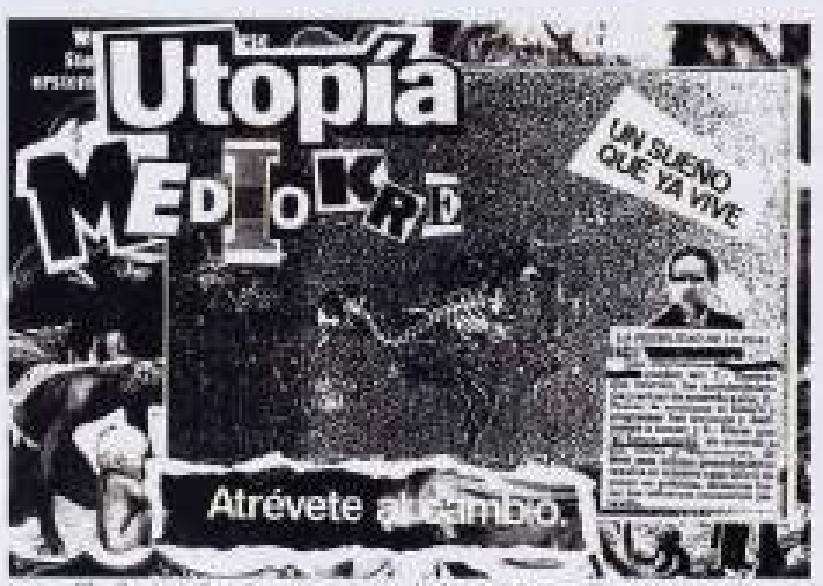

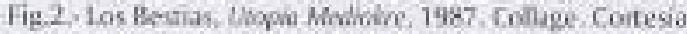
Arclino Alifedin Marupxx. ¿Como es el proceso de transición que decanta en la formación del Taller NN? (Fig. I).

Alfredo Márquez: Nuestra última acción como Bestiario fue en el Congreso Latinoamericano de Escuelas y Facultades de Arquitectura (CLEFA) en Cusco, en 1987, cuyo rema era un concurso de vivienda popular. Nosotros participames con un proyecto teorico-crítico de intervención publica completamente anárquico 'LIMA UTOPIA MEDIOCRE' (Fig.2) que proponía tomar los espacios del cen. tro de la ciudad (que en ese momento

2. Exate escisa bibliografia y restimonos sobre esta experiencia, tara una de las mas significanyas cronicas 50 -

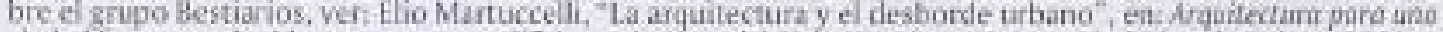

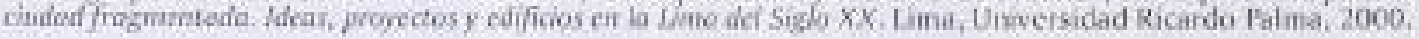


estaba siendo excavado) y participar con la población en un proceso de "invadir y construir" en función de lo que espontaneamente se fuera generando. Fue una respuesta que intentó decir que si existia algo reaccionario para nosotros era precisamente la arquitectura de interés social bajo la idea tradicional de construir casitas pobres para pobres en lugares pobres, sin alterar las jerarquias consolidadas de la trama urbana. Nuestra idea nunca fue generar un espacio permanente, sino disparar preguntas sobre lo que sucedia en ese momento. Lo diseñamos y lo enviamos, y resultó ser el primer proyecto descalificado por no cumplir las 'normas' del concurso de arquitectura. Posiblemente para los organizadores resultaba insostenible aceptar una premisa de tal estado de caos y libertad en medio de la violencia. Creo que algunos del colectivo esperaron que ganáramos 'algo' dada toda la energía depositaba, pero otros entendimos que nuestra victoria fue haber sido ninguneados. Recuerdo que el arquitecto Enrique Ciriani, quien por entonces venia de hacer un trabajo de vivienda muy importante en Francia, nos dijo que nuestro error habia sido concursar, que debiamos haberlo realizado sin ser parte del concurso. Yo no estuve de acuerdo, para mi lo que había que hacer para afectar la estructura era entrar en ésta. Luego de esa presentación se produjo una pelea al interior del grupo y nos dividimes definitivamente.

\section{ML: ¿Habia una diferencia de posiciones insalvable?}

AM: No diría insalvable, pero sin duda impostergable. No habia manera de seguir adelante todos juntos. Si lo ves en perspectiva el Bestiario era un proceso abierto al cual había entrado y salido mucha gente. En ese momento lo que se quebró fue como el núcleo central del colectivo. y eso provocó que algunos se fueran a reconstruir una casa de playa, y otros nos fuéramos a un pequeño local en el distrito de Jesús Maria sin tener idea de qué hacer exactamente. Pero era claro que ellos querian seguir haciendo arquitectura y nosotros ya no: queríamos pensarla. De alli nació $\mathrm{NN}$

\section{ML: ¿Cuál fue ese grupo de NN y cómo fue ese primer año de trabajo?}

AM: El núcleo medular de NN lo conformamos Enrique Wong ( $\mathrm{NN}$ detuchino). Alex Ángeles (NN acarajo), José Luis García (NN papalucho) y yo (NN a-c-falo). A principios de 1988 alquilamos ese local en Jesús Maria al cual llegaria Herbert Rodriguez y comienza a trabajar con nosotros. Herbert habia sido parte de la experiencia de E.P.S. Huayco (1980-1981) y es a través de ed que nos llegan las primeras referencias de ese grupo, desde 1984 que se involucra con el Bestiario. Luego en 1986 él participó activamente de la experiencia y acciones realizadas en la Carpa Teatro del Puente Santa Rosa ${ }^{3}$. Herbert trae al taller su ampliadora fotográfica, arma un cuarto oscuro y empezamos a producir una serigrafía bastante cuidada, lo cual marcó una diferencia para nosotros ya que nuestra producción nunca habia sido propiamente grafica. En todo ese tiempo se recibieron muchos encargos. Uno de esos pedidos fue un trabajo visual para acompañar la presentación del Informe de la Comisión Investigadora Sobre los Sucesos de los. Penales presidida por Roberto Ames, conocido como el "Informe Ames" de la "matanza de los penales" ocurrida en junio de 1986. durante el primer del gobiemo de Alan Garcia. Un encargo que resolvieron Herbert Rodriguez y José Luis Garcia a través de textos y esténciles, y asi operamos con varias otras cosas. Pero lo que yo más recuerdo de ese momento inicial es la participación frustrada para la revista Márgenes, editada por Casa SUR (Casa de Estudios del Socialismo) que era entonces el espacio de discusión del pensamiento de izquierda más importante que habia en Lima. Gustavo Buntinx, quien era uno de los editores, nos invita a realizar una intervención y nosotros le proponemos un triptico gráfico para el interior de la revista. Él nos

3 Bajo fa gestión inunicipal de Alfonso flatrantes flequierda Unidal se inauguto en 1986, pot iniciativa de Juan de Dios Radriguez, una Carpa Teatro en el extremo do la awenida Tacna al lado del puente Santa Rosa la cual albergo talleres de arte, educasion jopular, conciertios de rock, presentaciones de teatro y activismo cuiltural, Hi colectivo Bestiario se invohucro activamente en su construcción con deshechos y materiales reciclados en una dinámica de prodocción arquitectonica de participación sticial que venian desarmilando desde 1984. 
sugiere que lo acompañemos con un texto. Lo escribimos y recuerdo que el escrito arrancaba con la frase: 'LPor qué te expongo las visceras?'. Era un texto de escritura automática. hecho colectivamente donde nos preguntabamos por qué estabamos alli y qué implicaba ello. Curiosamente el texto terminaba con la frase 'porque ya no somos más bestias'. El triptico y el texto contenian una poética brutal y causó muchos problemas, finalmente fue censurado,

\section{ML: LEn qué se basaron para confeccionar esa pieza gráfica?}

AM: Te describo una de las imágenes: el rostro de Abimael Guzmain superponiéndose a la fachada de la CGTP /Confederacion General de Trabajadores del Perú| en medio de la Plaza 2 de Mayo, atravesado todo ello por un codigo de barras raspado y el número " $424242^{4}$. En la parte superior se leia 'Gran Paro', y en la parte inferior 'Paro fue Total'. Lo que sucedio entonces fue que la CGTP convocó a un paro nacional el 28 de enero de aquel 1988 para enfrentarse al gobiemo aprista de Alan Garcia, y el PCP.SL se monta encima para proponer que fuera un 'paro armado' en un intento de reconducir la protesta del movimiento sindical. Lo recuerdo porque nosotros fuimos como fotografos a la plaza el día del paro, pero además porque alli sucedió algo inédito: Sendero Luminoso dio la cara, por primera vez aparecieron con el rostro descubierto $y$ se manifestaron públicamente. Hubo entonces un enfrentamiento entre la CGTP y el PCP.SL, y luego un enfrentamiento de ambos con la policia ${ }^{\ddagger}$. Fue una situación impactante. El afiche producido fue una respuesta y memoria de ello.

\section{ML: ¿Y a qué se debio la negativa a publicar su propuesta?}

AM: Luego de enviasfo nos enteramos que habia generado una discusión interna y crisis en SUR, que habia posiciones irreconciliables frente a nuestra propuesta gráfica y textual. Creo que entonces nos dimos cuenta del enome poder de esa imagen. Habiamos introducido dimensiones muy sensibles en una discusión sin estar presentes. Ello provocó que Jesus Ruiz Durand se retirara en apoyo a nuestro trabijo, y que Alberto Flores Galindo, el lider intelectual de SUR y una de las mentes más brillantes del pensamiento de izquierda, hiciera cuestión de estado: es decir, que si eso se imprimia él se retiraba. Fse fracaso nos permitió comprender que nuestra textualidad y nuestros códigos visuales sobre la violencia dificilmente podian ser acompañados por la intelectualidad y la gente de izquierda, no de la manera en que lo estábamos haciendo. Pero tampoco teniamos ya la universidad, ni las calles y ni el municipio (que fue nuestro aliado en los tiempos en cue Bestiario trabajó en la Carpa Teatro). Eso nos hizo comprender de forma rotunda que el camino debia-ser necesariamente propio.

\section{"Crea-flexión y sistema idéico" (Habilitar to impensable)}

ML: Hay una conexiòn entre esa colabonacion no publicada para la revista Mórgenes y la pieza NN. PERÚ (mejor conncida como Carpeta Negra, 1988), la cud es un desinortaje de los imaginarios ideologicas que alimentaban el conflicto, pero tambien de la ficción del Estado y sus estructuras. Analizar la densidad y complejidad de la Carpeta Negra podria tomarnos toda la conversación. osi que tan solo llamaré la arencióa sobre alganos aspectos. NN-PERÚ es uno de los documentos que más intensamente registran las ambivalentias y desajustes de la guerra, y a riesgo de simplificar sus estratos podriamos decir que tiene dos bloques visuales diferenciados. (Figs. 3, 4 y 5 ) El primero titulado 'Mitomuerto', un despliegue de revatos de la cosmogonía del pensamiento de la izquierda

4 - 1 numero 424242 era el numero difundido por medios de conunitacion para incentivar denancias telefonica anónimas de presuntes terovistas

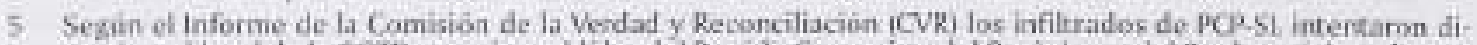
namitar el local de la CGIP y asesinar el lider del Partido Comunista del Penu. Jorge del Prado, originando una

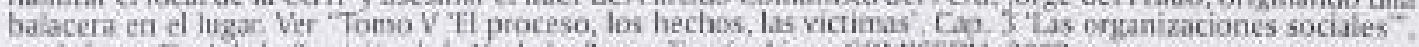

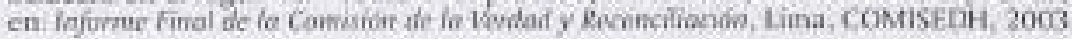


mallas, tintas, fotocopias y nos pusimos a imprimir alli. No teniamos idea de lo que era performance, pero lo que haciamos era performático: estábamos poniendo el cuerpo. Incluso si habia gente que queria aprender los involucrábamos en el proceso. Algo similar a lo que hacia entonces Coco Bedoya en las calles en Argentina socializando el proceso serigráfico como estrategia de comunicación colectiva, pero a quien aún entonces no conociamos. Lo que nos interesaba era que esa carpeta desatara una discusión públicit, por eso la idea fue que veinte intelectuales la adquirieran a precio de costo.

ML: ¿Quiénes eran estos intelectuales?

AM: Eran personas que considerabamos tenian algo que decir sobre la situación entonces vivida. Uno era el historiador de arte Gustavo Buntinx. Otro era el artista Jesús Ruiz Durand, quien había sido parte del proceso de la reforma agraria del gobierno velasquista en los 70. Otra fue adquirida por el historiador de arte Alfonso Castrillón, y luego otra por el teórico Mirko Lauer. Quizá también le ofrecimos uno a Maruja Martínez, miembro de Casa SUR. Otra persona que lo adquiere es Celeste Cambria, una amiga muy próxima feminista de Flora Tristán. Nos importaba que estuviera en lugares y con personas que pudieran detonar nuevas explosiones.

\section{ML: LEra exigir nuevas reacciones ante las circunstancias?}

AM: Exactamente. Poco antes de eso habiamos conocido al critico cubano Gerardo Mosquera, quien viene a dar una charla a la Universidad de San Marcos, Mosquera fue al taller, vio el trabajo en proceso y nos invito a la pre-selección para la Bienal de La Habana del año siguiente. Ya para entonces la guerra interna se estaba poniendo más dura. Para 1988 habian muchas más acciones del PCP-SL. en Lima, y amigos nuestros comenzaban a aparecer vinculados a esos grupos. Era imposible que la discusion no confrontara todo ello.

\section{"Guerra y poesía" (Estallar las verdades)}

ML. El final del proceso colectivo de Bestiario, un año antes, habia obligado entre ustedes una discusión personal sobre las direcciones de la guerra.

AM: Si. La disolución del Bestiario se acelera en medio de conflictos de tipo teórico sobre como entender la arquitectura, el arte, la vida y la política. Pero también existieron diferencias estrictamente personales sobre como deberiamos asumir el trabajo colectivo. Ello evidentemente sumado a la incursion progresiva de discursos anarquistas y comunistas en nuestras discusiones internas. Pero para 1988, ya entonces como NN, era imposible que no asumiéramos más honestamente la pregunta sobre qué es Sendero Luminoso, qué es el MRTA, qué está pasando en el Perú, en nosotros mismos, en nuestros cuerpos... Poco después dos integrantes de NN. Alex [Ángeles] y Enrique [Wong], decidieron replegarse para pensar y hacer otro tipo de cosas desde la reflexión arquitectónica. Ellos se plantean un retorno a la universidad y es en ese momento cuando José Luis Garcia y yo coincidimos con Juan Javier Salazar a fines de 1988, Juan Javier, quien también era ex-integrante de Huayco E.P.S., producia y realizaba entonces Memorias de la Lluvia, pelicula independiente a la que invitó a actuar a todos sus amigos e inclusive a nosotros. Alli decide dejarme su casa en Barranco para que la cuide, y es en ese lugar donde se reestructura posteriormente el colectivo y trabajo de NN En paralelo Enrique y Alex comienzan a discutir con los profesores de la universidad sobre los modos de entender politicamente la arquitectura. Ellos vuelven a la universidad para cuestionar sus estructuras, un lugar al cual yo habia renunciado porque me parecía estéril y más aún en un pais que se caia a pedazos. Creo que ellos perciben también esa incapacidad, dejan nuevamente la universidad y nos volvemos a juntar. Poco después, ya a inicios de 1989 , nos llega la respuest:

6 Sobre Fenando "Coco" Bedoya y las relaciones entre la experiencia del activismo argentino y las grácticas criti

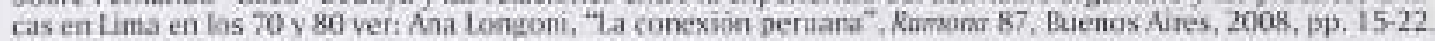


positiva de la Bienal de La Habana pidiéndonos un proyecto especifico para participar en ella por haber sido seleccionados.

ML: Habia pasado tan solo un anio desde el inicias de sus proyectos...

AM: En realidad todo pasó muy rápido. Uno sentía que se le iba la vida porque seguian ocurriendo miles de cosas en el Perú. Esa semana podias haber pasado al lado de un edificio que ya no estaba, porque habia sido volado con un coche bomba. La sensación de la inmediatez era otra cosa: la vida se estaba midiendo por lo que pasaba todos los dias.

ML: Ustedes tenian una opiniōn concreta sobre la izquienda clondestina?

AM: Creo que aún entonces habia en algunos de nosotros cierto nivel de permisividad reflexiva frente a las organizaciones armadas, no exento de cuestionamientos de todo tipo. La polarización armada era algo muy dificil de asimilar. Ninguno de nosotros, a excepción quizá de Herbert [Rodriguez], asumió el discurso de la Izquierda Unida. Nos era absolutamente insuficiente la noción de toma del poder, y que desde el Estado se gestaria alguna transformación significativa, Lo que siempre nos acompañó fue un claro discurso de anarquia.

ML: Te refieres a que no habia una opinión grupal (como NN) en contra de las grupos alzados en armas, que ese juicio era individual...

AM: Si, lo que digo es que no habia en nosotros un discurso unificado anti-Sendero Luminoso o anti-MRTA, salvo Herbert [Rodriguez] que si lo manifestaba y trabajaba abiertamente sobre ello. En nosotros la reflexión se procesaba de otra manera. Todos veiamos al PCP-SL o al MRTA como agentes de la violencia tanto como era el Estado, pero más allá de hacer un juicio categórico, nuestra discusión intentaba pensar las lógicas de la guerra desplegadas, eso era lo que nos parecia sumamente complejo. Y mas aún nos preguntabamos qué significaba hacer arte, arquitectura, acción cultural, en medio de una guerra.

\section{"Revuelta permanente y creación Eroica" (La destinerrancia)}

ML: Precisamente un aspecto crucial de la pieza NN-PERÚ es el modo en el cual desmantela la oposición entre militares y senderistas para evidenciar cómo la violencia ilegal provenía desde ambos bandos.

AM: Yo creo que en ese momento no sabiamos lo que podia ser la deconstrucción o sus estrategias, pero de alguna manera lo estábamos haciendo. Se estaba imponiendo un discurso que no tenia nombre propio: era algo que nos estaba saliendo de las venas.

ML.: Esa rabia y voluntad iconoclasta era tambien una nueva praxis que enterge desde todos los ámbitos creativos imaginables a nivel local, generando circunstancios donde la organizacion politica no obedece ya a la teoría sino a las rupturas generadas desde la experiencia y la vida diaria. Sin duda ustedes estaban mirando otros procesos similares de politizacion desde el arte.

AM: Claro, era parte de nuestros diálogos la problematizaciōn de los aciertos y caidas de los constructivistas rusos (arquitectos, artistas y poetas) que participaron activamente de la agitación revolucionaria en las postrimerias de la Rusia zarista, y su posterior incorporación entusiasta a la Unión Soviética tras el triunfo de la revolución bolchevique. que sin embargo significó su destierro y en algunos casos la propia muerte. $\mathrm{O}$ también los textos poéticos y politicos de César Vallejo a través de publicaciones (no editados por êl) como 'El Arte y la Revolución'o 'Contra el Secreto Profesional', introducidos en nuestras discusiones por el poeta y amigo Roger Santivañez, que hacian parte de un cotidiano para pensar y repensar ¿qué pasaba con los artistas e intelectuales en un momento de agitación politica y bélica como en la Rusia del '17 o en la España del '38? 


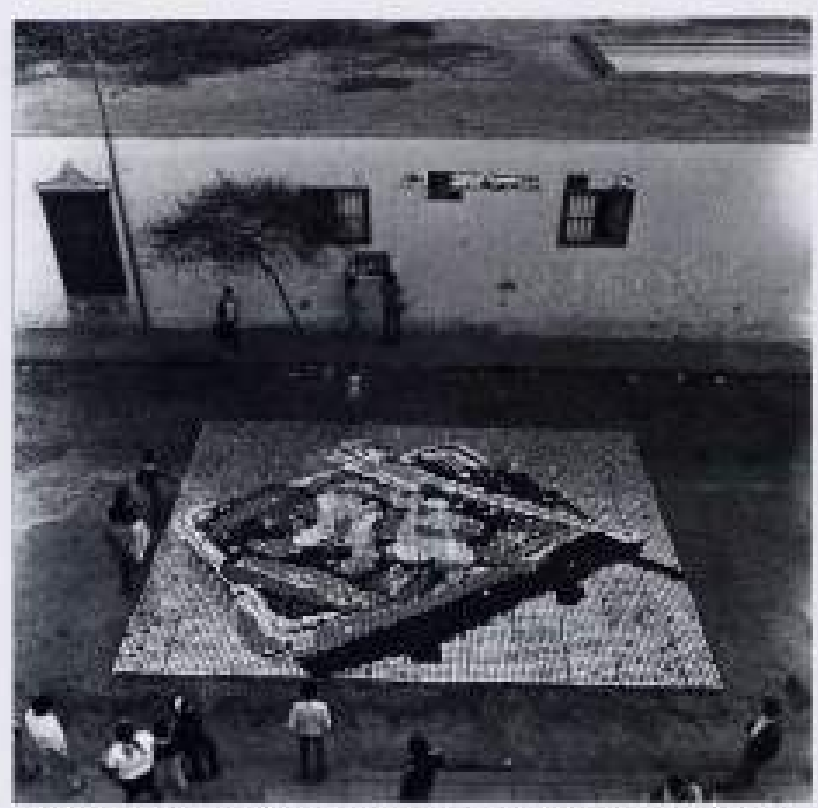

Fis.6. F.P.S. Huacco, Arte al Pava 1980. Panturas solire 12,000 latas de ledse cvaposada. Cortesia: Francesco Mariotti.

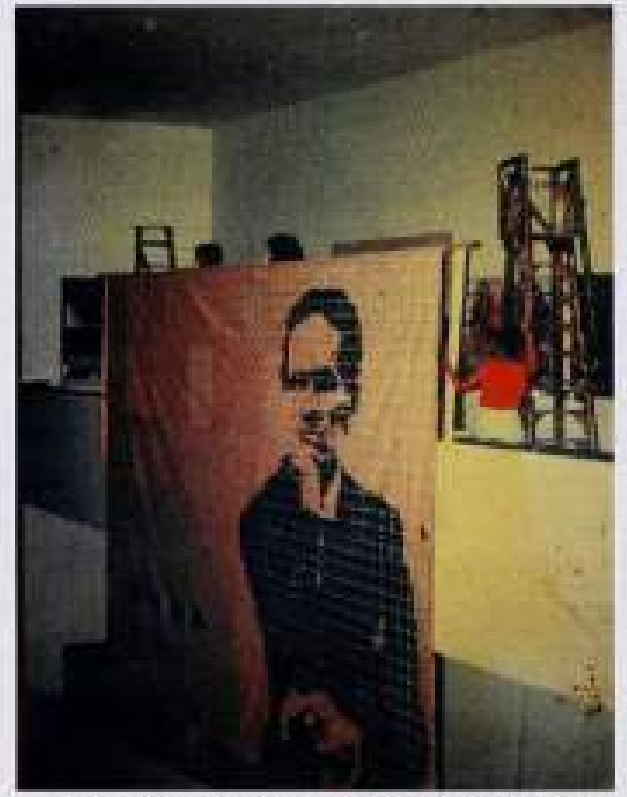

Fig.7. NN, befloyo Destracoideconstuccion, 1969 Vista de insalación. Mia. Alecal de ta Habanal

Precisamente nuestro proyecto para la $3^{\circ}$ Bienal de La Habana reflexionaba sobre el papel politico de la imagen en la construcción publica de la actitud del intelectual frente a la revolución. Poco tiempo antes habia aparecido una fotografia de Robert Capa donde se mostraba, entre otros intelectuales, al poeta César Vallejo con el puño en alto en medio de un Congreso de Escritores Antifascistas (1937). Se trataba de ana imagen desconocida. Lo que propusimos fue una 'destrucción' y 'construcción' de la representación del poeta, enfrentando su imagen tradicional contemplativa frente a la del Vallejo militante y combativo. De forma indirecta la pieza intentó ser un homenaje a E.P.S. Huayco que ya había utilizado su imagen en 1980, y si ves la estructura de células que conforman nuestra serigrafia remite al tramado de las 'salchipapas' de 1980\%. (Fig.6) Sin embargo, la complejidad del proyecto original impidió que se realizara por completo. Nosotros disenamos un cartel serigráfico donde lo que construía la figura del 'Vallejo contemplativo' era la repetición en una trama cuadricular de la imagen del 'Vallejo combativo', realizado sobre una trama de hoces y martillos construidas por pequeños puntos, La pieza era una bandera gigantesca de siete metros por cinco que caía como un telón. (Fig. 7) La idea era que esa 'bandera' luego se tenia que arrear para colocar otra encima con la imagen del 'Vallejo combativo', construido por células del Vallejo contemplativo' y múltiples hoces y martillos enrojecidos... era como un juego de construcción y superposiciones. Finalmente eso último no se hizo. En ese instante Enrique [Wongl que había viajado conmigo regresó a lima y yo me quedé en Cuba por poco tiempo más.

ML: Adenas de ese proyecto ustedes realizan otras piezas en serigrofic en Cuba...

AM: Si. Lo que te he descrito es la idea que llevamos a la Bienal pero viajamos con la Corpeto Negra bajo el brazo, y fue ésta la que generó más impacto. Aldo Menéndez, que era el director del Taller de Serigrafría René Portocarrero, se quedó alucinado con el Mao con los labios pintados y nos invitó a hacer una versión nueva para la carpeta editada en el "3er. Encuentro Internacional de Serigrafia". Fsa nueva imagen titulada "Kiva ei Maokmo" (1989) (Fig 8) se gesta y se produce en Cuba. Pero adicionalmente hicimos dos grabados más. El primero es la pieza

\footnotetext{
7 La 3" Bienai de La Habana 'Tradicióny Contemporatreidad' se presents del 27 de octubre al 31 de diciembre de 1989.

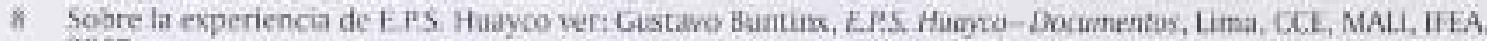
2005.
} 
titulada Vallejo (Destrucción / Construccion) (1989), que contrasta la imagen de los Vallejos contemplativo y combativo con el signo de la hoz y el martillo, $Y$ otra serigrafia de la cual no queda rastro, en la cual aparecen dos policias arreando una bandera de Sendero Luminoso, impresa en dorado sobre dorado. Esa pieza también la traje a Lima pero ta desaparecieron quienes me detienen en octubre de 1984.

ML: No es un detalle menor que entonces la Bienal de la Habana sea la tinica bienal internacional organizada por un pais socialista, configurando una plataforma de discusion desmarcada de las exigencias del mercado en una convergencia de escenarios perifericos: América Latina, Asia, Africa y Medio Oriente. ¿Como fue su relación con los otros invitados a la Bienal? ¿Y qué reacciones hubieron ante la caída del Muro de Berlín producida pocos dias después de inaugurada lo Bienal?

AM: La mayoria de los artistas reconocidos invita. dos eran mucho mayores que nosotros y con ellos nuestro contacto fue limitado?. Sin embargo, los

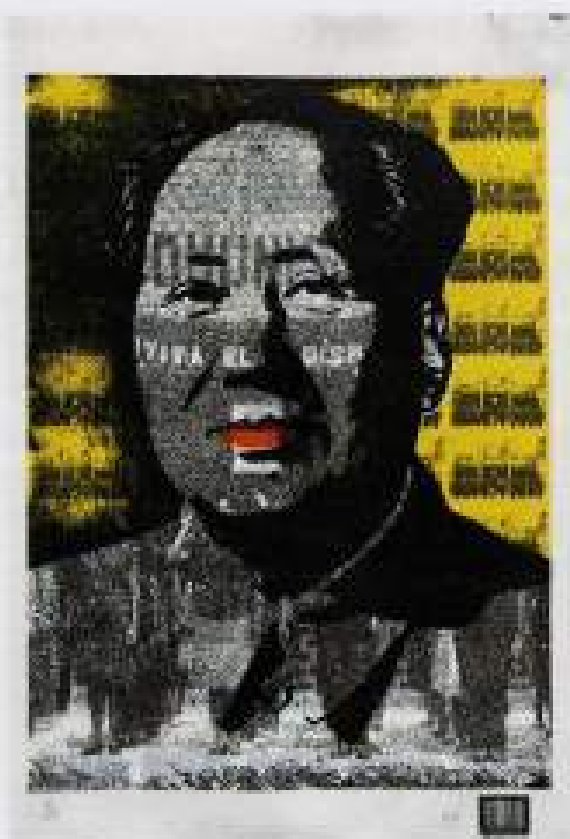

Fig.8. NV, "Yinuel movismu", 1989 Serigrafia suber papel. $76 \times 56 \mathrm{~cm}$ Cortesia Ardamo Affredo Marquez. artistas locales eran jóvenes y la empatía con ellos fue inmediata. En varios momentos nos sentimos parte, viviendo la utopia crítica frente a la revolución establecida. Es decir, para ellos el Estado oficial era la 'falsa revolución', y nosotros compartimos la locura de esos jóvenes que buscaban un espacio de libertad casi salvaje, drogandose al borde de las detenciones, repudiando al estado abiertamente. Varios de ellos tomaron nuestra figura de Mao como imagen de la contestación, la pusieron incluso en sus ropas. Era muy impactante entender cómo en el imaginario de un joven cubano la imagen de Mao estampada podia ser una sacada de lengua al gran régimen pro-soyiético, cuya vulnerabilidad estaba puesta en cuestión por la caída del Muro, Y comprender, al mismo tiempo, que esa imagen de Mao en Perú podía significar la cárcel o la muerte. O incluso sentir cómo la hoz y el martillo de nuestras imágenes podfan alli percibirse como una imagen de diseño o mera propaganda, o acaso una referencia incómoda a las reformas de apertura liberal de Gorbachov y la Perestroika, pero que en Perú se trataba del icono más evidente de apología al terrorismo'. No estoy diciendo que ellos al estampar la imagen de Mao se asumieran como maóstas, sino que entendian la potencia de devolver a la mirada pública un signo reprimido, negado, y con ello abrir el acceso a una realidad que perturba. Ver como esas operaciones visuales eran capaces de desencadenar reacciones inesperadas, sentir esa dimensiôn performativa de la politica fue un aprendizaje incalculable. Creo que eso nos mostró que si existia una vitalidad posible desde el pensamiento de izquierda, pero que ésta estaba claramente en otro lado, que emergia y circulaba de otras maneras. Pocos años después nos tocó también enteramos sobre las detenciones de algunos de estos jóve. nes que nos acompañaron en La Habana, como la del cubano Ángel Delgado que poco después en una performance defeco en el diario Granma, el órgano oficial del Partido Comunista de $\mathrm{Cuba}^{10}$.

9) Sobre ello yer Miguel h, Lopex. Discarded Knowiedge: Peripheral Bodzes and Clandestine Signals in the

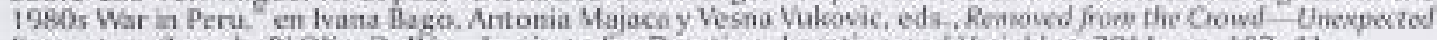
Encotmlers, Zagreb, BLOK y Delhe-institute for Duration, Location and Variables. 201 1, pp. 102-41.

10 La acción de Delgado se desiarnolló en 1990 en la inaigaración de la exposición 'El objeto esculturado' en el Centro de Desar nollo de Artes Visuales. Delgado fue detenido por la policia, acusado de escindalo píblico y condenido a seis meses de prisión. 


\section{ML: ¿Y fuera del ambito artistico hubieron reacciones oficiales ante la caida del Muro?}

AM: Si. en medio del evento ocurre un acto simbolico organizado por el Estado Cubano que nos ubica nuevamente en el poder de lo simbolico. Cae el muro 19 de noviembre) a pocos dias de inaugurado el evento y poco después Gorbachov se reune con Ronald Reagan en un portaviones en la Florida, es decir, frente a Cuba", Inmediatamente des. pués de eso el Estado Cubano ordena la repatriación de los restos de los caidos en la gue. rra civil de Angola. a la cual había enviado soldados desde mediados de los anos 70 . Una guerra en la cual Angola intentaba liberasse del colonialismo portugués, y que Cuba junto con paises no-alineados apoyó dando soporte al grupo marxista-leninista de esa contienda". Lo que estoy diciendo no puede perder de vista que el proyecto comunista es ante todo un proyecto internacionalista proletario': no existen fronteras, todos los proletarios se unen para tumbar a la burguesia. De lo cual se desprende que para ese imaginario no puede existir comunismo de un solo lado: o existe para todos o no existe. El retorno de los cuerpos de los combatientes en Angola a Cuba fue claramente un acto estratégico para reagrupar simbólicamente sus fuerzas ante las implicancias del derrumbe del bloque socialista de Europa". Esa sola acción provocó una comunicación colectiva dificil de ver en otro tipo de Estado, afirmando una defensa ferrea del cuerpo socialista y de su misión internacionalista.

\section{"Felicidad compartida y suicidio colectivo" (Voluntad de otra cosa)}

\section{ML: LComo retoman el trabajo colectivo en Lima luego de su participacion en Cuba?}

AM: Yo volvi a mediados de diciembre, luego de un mes y medio. Al llegar de La Habana cerramos el taller fisicamente porque la casa en donde estábamos fue vendida. Asi que la parte operativa del taller fue mudada a la casa de los padres de Alex $\mid$ Ángeles $\mid$ y con. tinuamos haciendo pequeños proyectos, pero la situación era cada vez más dificil. En lo personal mi segunda hija habia nacido y de pronto no teníamos casa. Estuve dos meses buscando un lugar para vivir y en ese lapso conseguimos también otro espacio para el taller. Había voluntad para seguir, pero era más dificil, $y$ nuestras diferencias eran cada vez más intensamente vividas.

ML: Durante esos trances ustedes reciben la visita de la crifica chilena Nelly Richard en su taller. CConocian su escritura o fa produccion critica de paises como Chile o Argentina frente a las dictaduras de ese momento?

AM: Conocimos el trabajo del grupo CADA por la revista Utopicos a inicios de los 80, y aun mas durante el proceso del Bestiario. Además en 1988 conocimos a Eugenio Dittborn quien habia expuesto el ano anterior en la III Bienal de Trujillo. Del mismo modo tuvimos contacto con el chileno Juan Davila quien se acercó a nuestro taller y de quien nos impactó fuertemente su deconstrucción de imágenes desde el cruce de sexualidad y politica. Incluso recuerdo poco tiempo después la visita del argentino Juan Carlos Romero, quien entonces era parte del grupo Escombros, que ofreció una lectura en Casa SUR y que terminó en una discusión muy áspera entre nosotros sobre los modos de operar en medio

11 En realidid este enctientro se prodijo entre el sucesor de Reagan, George Hush, y Mihail Gorbechow, durante el 2 y 3 de diciembre en el buque S5 Maxim Corkiy en la isla de blalta en el Mediterraneo, en el cual suscribjeron un acuetdo de cooper ación que puso fin a la Guerta fria. Un encuentro entre Corbachov y ej presidente Ronald Reagin, junto al reciente electo Bush, habia ocurrido en dictembre de 1988 un Nueva York, $y$ antes. entre Reagan y Gorbachow en mayo-junio de 1938 en Moseu.

12. El conflicto central de ta zuera civil en Angela desde 1975 tumo como adwersarios al Movimiento Popular de Liberacion de Angola (MPL A de izquierda, y el Frente Nacional de Laberación de angola (F) Al de derecha. Fl ejercito eubano junto osn li guerrilla socialista de la SWADO IOrganización Popular de Africa del Sudoeste? de Namibia apoyaron desde el inicio al MP'LA. hasta 1988 que Angola x Cuba firman un acuefdo bilateral para at retiro de lis tropss cubanas.

13 . Fsta acción titulada 'Operación Trituro' fue una ceremona tinebre nacional el 7 de diciembte de 1989, en ef Mausoter de fir cacahual en la Habana, como degpedida de los caidos en las misiones en Angola, 
de la violencia. Todos estos encuentros nos permitieron repensar nuestros procesos. Era reconfortante sentir que sin conocernos podiamos estar articulando operaciones criticas parecidas en ciudades distintas. Si mal no recuerdo Nelly Richard llega a nuestro nuevo taller a través de Gustavo [Buntinx]. Este ya no era un taller colectivo sino un espacio con habitaciones 'individuales' donde cada uno trabajaba por su lado. ${ }^{14}$ Su visita es en un momento de crisis interna y de esa conversación guardo una sensación muy amarga ya que anunciamos nuestra disolución como grupo de una forma sumamente dura. Tengo la impresión que el encuentro debe haber sido tosco y decepcionante para ella, ${ }^{15}$ Ya no éramos el NN de un año atras.

\section{ML: ¿Y esa sensación de decepción era algo que té podias compartir?}

AM: Si, claro, Creo que ninguno de nosotros se planté radicalmente 'disolver' NN, y acabar para siempre el asunto. La situación reclamaba que cada uno tomara una nuevi libertad para hacerlo a su manera. Para nosotros no habia modo de entender nuestra realidad sin atravesar una reflexión viva sobre la guerra, y eso implicaba poner sobre la mesa las cosas que acontecian: no habia acuerdo de cómo ver eso, era claro que debía verse y discutirse pero no existia consenso desde dónde y cómo verlo. $Y$ esa toma de posición obligó a que dejáramos de presentamos como NN. Llegamos a una situación en la cual el acento que cada uno podia poner sobre un determinado asunto era capaz de lastimar la noción del otro sobre lo mismo.

\section{"El arte plop y la línea lila" (Descompletar el pensamiento)}

ML: Me interesa volver sobre la relacion teorica y estetica del Taller NN con la vanguandia soviética de inicios de S. XX, no solo por la proximidad de ciertas estrategios a través del montaje, sino por la manera en que asumen la funcionalidad politica de lo estético.

AM: Conocimos la experiencia de la vanguardia soviética todavia siendo Bestiarios, pero ya para 1989 nuestra retórica y voluntad constructiva habian asumido más claramente esa filiación. En 1990, en una exposición organizada por Gustavo Buntinx en el Museo de Arte Italiano titulada Restauración / No Restauración, algunos de nosotros somos invitados a participar y una de las cosas que hicimos fue precisamente una serie de estructuras por las cuales tu accedias a una armazón de fierros en espiral ascendente, que era una cita directa a Tatlin. El discurso de la destrucción de los paradigmas del arte y la construcción de una realidad social y cultural nueva, esta noción utopica que subyace al trabajo de los constructivistas. era algo que nos alimentaba. Pero de alguna forma teniamos la amarga sensación de que quiza nos podia pasar lo que a ellos en la Union Soviética de los 20 y 30: que ibamos a ser barridos por aquellos que supuestamente nos visibilizaban como sus afines.

ML: Es duro pensar la tragedia que acompaña ese horizonte de experimentación revolucionaria, sofocado por la liegada de Stalin al poder que pone d arte al servicio del aparato burocratico. Para las autoridades socialistos esa 'vanguardia' era un arte inconjprensible para las masas, incapaz de responder a las demandas de un 'arte revolucionario'...

AM: Es interesante lo que mencionas porque en las conversaciones que he tenido con gente que podria asumirse como proxima al PCP-SL. las reacciones frente a nuestro trabajo eran siempre de indiferencia, cuando no de abierto rechazo. Decian que nuestro arte era

14. Da primera visita de Nolly Richurd a Perú se realiza en 1989 en la III Bianal de Trujillo, pasa el coloquio Modernifod y Pruvincia, organizacóo pot Reyuatdo Ledgard y Gustavo Buntinx Entre otros artistas chilenos asistentes a Tujillo se enculentras Jose Balmes, Eugenio Dittborm, Cartus Leppe y juan Davita.

15 En la memoria de este encuesuro. Gustowe Buntinx recuetda tambien la presencia del artista chileno fuan Davila. 3 coincide en que la impresion de Richard fue de desencanto. Sin embargo seiala que en la percepción de Richard la compleja obra de NN tensionaba y discutia las manifestaciones ideologicas más explicitas que en aquella ocasion 2 gano de sus mienbros podia sostener. Conversación teleforica, Lima, 23 de abril de 2010 . 
un 'arte burgués' y que nuestros paradigmas, nuestra movilización y nuestra visión de la revolución que ellos /Sendero Luminoso/ estaban desarrollando no eran ni siquiera crítico. sino algo muy infimo o insolente.

ML.: Ustedes realizan una maqueta de Vallejo (Construcción / Destrucción) para la Bienal de La Habana en la cual reproducen una frase de Vallejo: "Revolucionariomente, los conceptos de đestrucción y construcción son imseparables". En eso frase tomada de El Arte y la Revolución (1934) Vallejo alude a la creación de una nueva realidad desde la perspectiva dialectica, pero cayas reverberaciones en el Perú de ese momento estarian teñidas de tragedia. Es impasible no reconocer que el discurso prestantamente libertario de PCP-SL es ea realidad el de una razón totalitaria, tan ideolögicamente colonizada como la nociōa de burguesia que pretendia

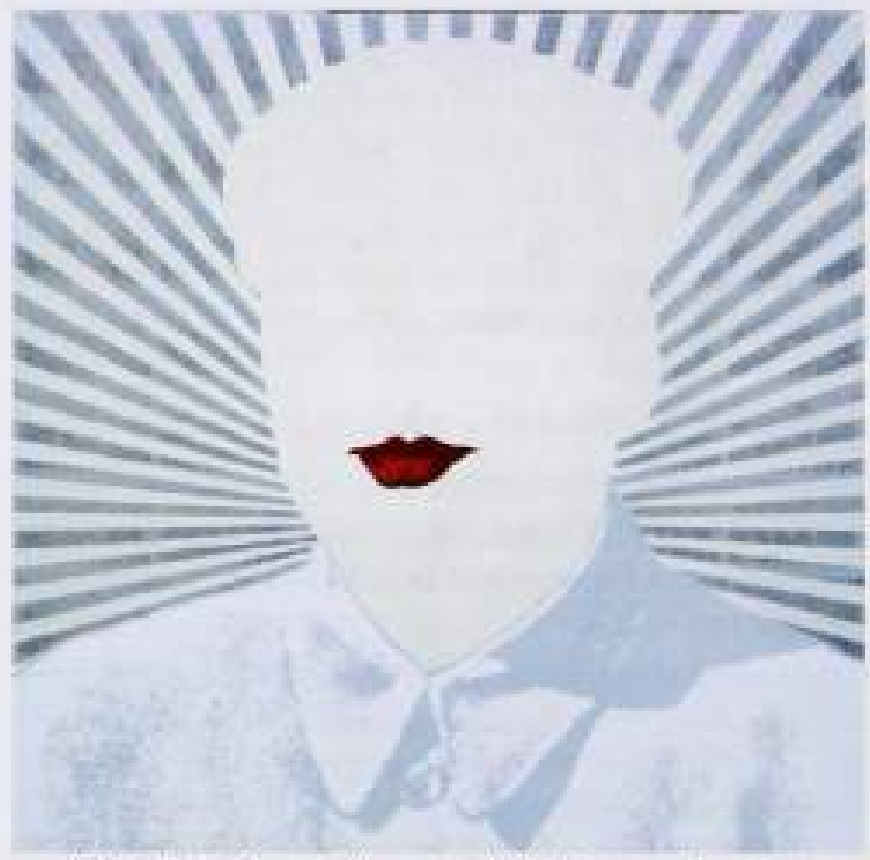

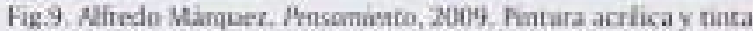
serigrafica sobre lienzo, 380 > $180 \mathrm{~cm}$. Cartesia: Alfredo Marquex. enfrentar...

AM: La noción principal para el PCP.Sendero Luminoso era la del 'pensamiento', the ese concepto me parece clave $-y$ no en vano el título de la última serie que hice se titula asi. (Fig 9) Para los ojos de PCP-SL no existia nada más allà de ello: todo tenía que recorrer la 'línea roja', la 'posición correcra'. De esta manera su entendimiento del arte pasaba por una funcionalidad ilustrativa del discurso. Se trata de algo tan centralista como concéntrico, y no se si 'totalitario' sea una palabra suficiente para expresar eso. Es muy contradictorio porque el marxismo como concepto filosófico parte de la dialéctica, y el PCP-SI. en su discurso te habla de dialéctica, te dicen que debe existir la lucha de contrarios. Es verificable en sus textos, pero no en su práctica. Ellos pasan por encima de todos, incluso por encima de si mismos. No quiero expresar un juicio moral con lo que estoy diciendo, pero si intelectual. Por eso considero que visibilizar las prácticas que desarrolló alguna vez NN o cualquiera de sus participantes, desde la plástica o la arquitectura, como algo que fuera funcional al discurso de Sendero Lurninoso es descabellado.

\section{"El estado-niño y el hombre político" (t.o indecidible)}

ML: En 1992 la captura de Abimael Guzman, el lider del PCP-SL, intensifica una persecución de presuntos agentes vinculados a los grupos dandestinos, involucrando a varios personas que en momeatos anteriores habian prestado atencion o generado discursos criticos en formo a la guerra, entre cllos tu mismo y tus companeros del colectivo.

AM: Si. Es importante tomar en cuenta que a Guzmán to detienen en casa de Carlos Incháustegui y Maritza Garrido Lecca. Maritza era una bailarina de la clase media alta y de la esfera cultural limeña, amiga querida y conocida por mucha gente, y Carlos

16. Tambien denominado 'pensamiento gisa' o pensamiento Genzalo' en aluston al camarada Conzalo', seudó. nimo de Abimael Cuzmán Reinoso, líder maxims del PCP.ST hasta 1992, año de cu captura. 
Inchâustegui habia estudiado arquitectura con nosotros y habia acompanado el proceso del colectivo Bestiarios de la década anterior, y también participó como NN del proyecto de La Habana. Esa situación abre la persecución al máximo y a distintas personas las intentan involucrar irresponsablemente. Además en 1992 es un año de radicalización extrema de la violencia desde ambos bandos, y para entonces no parecia existir una tercera via: todo estaba siendo perseguido, atacado, encarcelado y muchas voces tuvieron que autosilenciarse por seguridad. Ya para entonces la movida subterránea estaba languideciendo y el movimiento poético era el inico sobreviviente fragmentado en espacios alternos.

ML: Hablemos de tu detención. Lo que sucede en terminos fócticos es que en octubre de 1994 el Estado te secuestra y te somete a un primer juicio inconstifucional en el cual te sindican como ternorista. Existe incluso la idea que te capturaa por la imagen de Mao con los labios rojos que es leida como 'apologia:

AM: Esas 'razones' las construyeron en la elaboración del juzgamiento. Aunque suene ridículo, una de las cosas más jodidas para mi era entender que en realidad no habia sido detenido por mi trabajo o por mis ideas. Fllos construyeron su carceleria para mi como una suma atropellada de circunstancias, no es que hayan detenido a Alfredo Márquez 'el artista', para nada. No existe ninguna gloria artistica de por medio, Habia una 'cacería de brujas' y hubo un operativo de inteligencia donde quisieron hacer aparecer a mucha gente vinculada al arte y a la universidad como los uiltimos reductos de Sendero. No podemos olvidar que antes de ser yo detenido el Estado habia ya anunciado al PCP.SL como una organización derrotada y desmantelada, y que Guzmán habia prestado su imagen y discurso a un Acuerdo de Paz con el Estado bajo la dictadura de Fujimori y Montesinos.

En mi caso, como en el de tantos otros, se trato de un secuestro abortado para justificar lo que vendria después: la perpetuacion de la dictadura de Fujimori luego del autogolpe de 1992. Además yo en ese momento, desde el ejercicio plástico, no estaba tan activo como en anos anteriores. Aunque pocos dias antes de mi secuestro acababamos de realizar con el sociólogo Sandro Venturo un evento en la Universidad Católica donde se vinculaban las prácticas okupas españolas con la movida subterránea y la Carpa Teatro en la lima de los 80 . Y un poco antes de eso incluso se celebró el $10^{\circ}$ Aniversario del Bestiario en un evento público. No hablamos de grandes eventos, eran cosas pequefias con un radio de acción que implicaba solo a las personas que les importaba aquellas experiencias tempranas, aunque luego me di cuenta que ya para entonces yo estaba siendo seguido.

Volviendo a tu comentario: ellos al momento de justificar la ilegalidad del arresto se escudan en la imagen de Mao. Algo que me hace muy feliz, es que nuevamente se activa la polivalencia de esa representaciòn, la polisemia latente de la cual estábamos hablando. La interpretación punitiva de esa imagen es la que sostiene mi presencia en la cárcel (como apologia), pero es tambiên esa interpretación abierta la que permite luego que salga de ella...

\section{ML: LTe refieres a su rol como evidencia en el juicio...?}

AM: Claro. Pero eso sucede en un segundo momento a través del extenso proceso de entrevistas y revisiones efectuado por la "Comision de Indulto". El primer momento me llevó a la sentencia, $y$ alli todo fue un montaje militar y con jueces sin rostro en el cual no habia ninguna posibilidad de defensa. Pero ya para el segundo momento si hubo la posibilidad de utilizar como defensa estos testimonios y alegatos artísticos y pedidos de liberación de diversas personas, Entre varias otras cosas recuerdo que la historiadora puertorriqueña Mari Carmen Ramirez escribe una carta donde explica la dimensión artística de la pieza por la cual querian acusarme como terrorista. 


\section{ML: LCómo llega eso carta en poder de los abogados?}

AM: Yo estaba encerrado en ese momento, pero creo que Gustavo [Buntinx] habla cos clla sobre la situación. Y ella escribe una carta dirigida a los jueces ya que habia tenido acceso a esa y otras obras. No tengo certeza pero eso puede haber sucedido en 1996 y esa fue como una de las piezas importantes en la defensa" Aunque finalmente mi sentencia se dicta a fines de ese año. El texto de Mari Carmen no contenia una sustentación extensa sino tan solo un destinde con cualquier filiacion 'terrorista', que los jueces estaban buscando y su argumentación consistió en leerlas como imágenes dentro de la historia del arte, en diálogo con las obras de Andy Warhol, por ejemplo.

\section{ML: Aunque ustedes no las hayan realizado como parte del imaginario 'pop', esa lectura ciertamente} podia ser establecida...

AM: Si, claro. También Alex [Ảngeles] preparó una cantidad de imágenes para contextualizar esa imagen con otras obras de arte. Otro argumento para sindicarme como terrorista' utilizaba mi visita a Cuba de 1989. Es decir, si la experiencia del conflicto armado peruano que traducimos gráficamente generó una incisión en el imaginario marxista en La Habana, lo mismo terminó ocurriendo pero a la inversa: desde Lima mi paso por Cuba cra entendido como un signo inequivoco de complicidad con los movimientos comunistas clandestinos. Esto es algo interesante de tomar en cuenta hoy, cuando en Cuba al parecer existen opiniones que reniegan de la presencia de NN en esa Bienal por aparentes vinculos con el PCP.SL.

Como ves la situación era una comedia: mi propio abogado repetía que icómo era posible esgrimir ese argumento si a mi me acusaban de tener vinculos con Sendero Luminosol. y el cliscurso maoísta es completamente antagónico con la posición pro-soviética de Cuba. iEra el teatro del absurdol Pero es alli donde mejor percibes la dimensión poderosa e inmanejable de lo simbólico, los cortocircuitos que estaba generando incluso en el sistema legal o jurídico.

Finalmente esos esfuerzos se encaminaren cuando mi caso es revisado por la "Comisión Ad-Hoc de Indultos para casos de personas injustamente detenidas por terrorismo y traición a la patria", esta comisión estaba liderada por el padre Hubert Lanssiers, quien además habia asumido como algo personal mi defensa. Finalmente dijeron que el Estado se había equivocado conmigo: que podía ser contestatario, anárquico, crítico del Gobierno, que podia estar trabajando con simbolos y representaciones que personificaban los grupos beligerantes en el conflicto interno. pero que no tenia ni participación ni vinculos reales con Sendero Luminoso. $Y$ soy liberado como otras 478 personas a lo largo del tiempo de funcionamiento de esta comisión.

\section{"El huevo y la gallina" (Un tiempo dentro de otro)}

ML: Duronte ta tiempo de detención pintos el cuadro La Pachakuti (Like a Virgen) (1997), uno reconversión (post)barroca profundamente transgresiva de una constelación de referentes andinos y prehispánicos pero también coloniales y contemporáneos -como una vedette de color azul transfigurada en el limite de lo mistico-que desestructura los modelos de lectura del mito incaico de inversión del mando y forzando una desacralización de la historia (Fig. 10).

17 En una comxersaciòn reciente con Gustavo Buntinx esta version ha sido cormoborada, sebialando que fü aproximadamente entre 1995 y 1996 que él solicitó alçunas cartas para los abogados a fin de que sirvieran de aval iremacional sobre el caracter cultural de la producción de NV, senalando adicionalmente la existencia de otros intentos de apoyo entre las cuales cabe mencionar una carta circulada en la escena artistica de lim. baciendo un pedido de indutro. El testimonio de Buntinx seàali que adensás de ta bistoriadora Mari Carmen Raminez, muy posiblemente tambies obtuvo cartas del criticu cubano Gerando Moscuera, y acaso también de astista y escritor uruguayo Lais Camnitzer y el critico argentino Marcelo Pacheco. Cunversación telefónica. Hima, 23 de abril de 2010 . 
AM: Sí. En realidad esa pieza es provocadia por el recuerdo de una conversación con Fernando 'Coco' Bedoya que tuvimos en 1993 mientras él preparaba su exposición para la galeria Parafernalia en mi taller 'Made in Perü. Coco ya venía de su experimentación con el grupo Paréntesis (1979) y su proximidad con Huayco E.P.S. en Lima, pero sobre todo arrastrando su experiencia con el activismo argentino de los 80 . Recuerdo que en una de esas conversaciones él me dijo que le encantaria plasmar en una sola imagen todos los distintos tiempos por los que habia atravesado la historia del Perú. Y yo me quedé con esa imagen, me parecia de una poesia muy poderosa. ¿Cómo colocar todos los tiempos trastocados en una sola imagen?

ML: Introducir un tiempo dentro de ofro

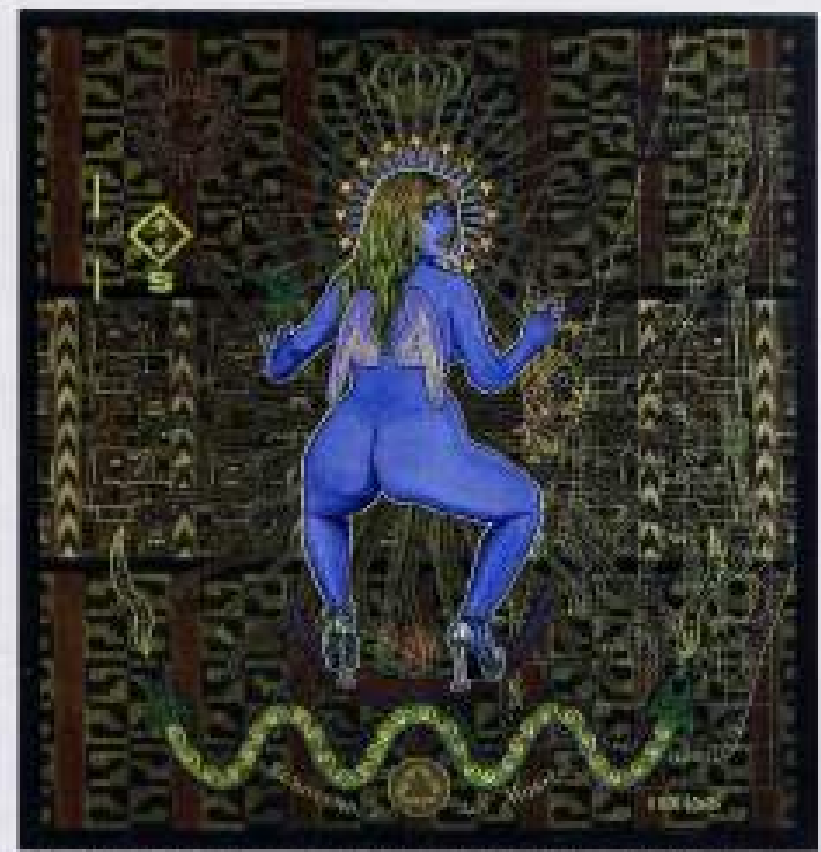

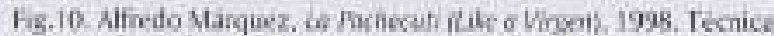
mista snbre rela, $150 \times 139 \mathrm{~cm}$. Coleccion Nicromuseo it na fonde

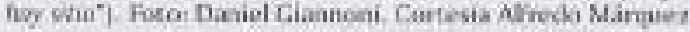
tiempo puede generar algo explosivo...

AM: E implosivo a la vez. Utilicé la estrategia de la sedimentaciôn sublimada, es decir como si existiera una serie de estratos acumulados en fricción que emergen y se ocultan simultáneamente. Alli descubro otro modo de producir discurso, porque hasta entonces toda la producción de NN habia sido con la iconicidad activa de la guerra, pero era evidente que no podia hacer eso dentro del reclusorio. Tenía que descubrir otro modo de hablar de política con elementos que fueran politicos pero no tan fäcilmente reconocibles.

ML: Cóno ves en perspectiva tu procesoy tiempo de encierro, y las refaciones que alli se establecieron.

AM: Quisiera que seamos concientes que en mi caso yo contaba con un privilegio. No estoy diciendo que me trataran 'bien', como si pasaba con los dirigentes de los grupos armados: a mi me enceraron y era alli un miserable cualquiera. Hablo de otro tipo de privilegio: una cosa es ser un campesino quechua hablante secuestrado en la puna y llevado a Lima para ser juzgado en un idioma que le es ajeno, y tan solo sentir una distorsion de voces y de cuerpos que no eres capaz de comptender antes de saber que te sentenciaron a cadena perpetua, y otra cosa muy distinta es ser un limeño clase media con formación universitaria. Yo tenía las herramientas con las cuales habia estado trabajando y un grupo de amigos afuera, pero muchos de ellos carecian de familia o recursos. No reniego de mis privilegios. por el contrario, me parece que debemos asumirlos como una responsabilidad. Por eso considero importante la experiencia que comparti con estas personas. Cuando hablo de la prisión con toda dignidad estoy tratando que se entienda que el Estado no triunfó: si. nos metieron a la cárcel ilegałmente, nos humillaron, nos volvieron tuberculosos, pero la gente ha sobrevivido y siguen haciendo sus vidas. Creo también que una cosa importante de sopesar de ese proceso son las estructuras de las organizaciones armadas que funcionaban adentro. Es una máquina que opera a través de prácticas y ritos, y negarte a participar de eșas prácticas siendo un detenido aparentèmente bajo la misma condición es algo bien delicado. Esas retóricas, en esos modos de ser y de hacer, lo simbólico cumple nuevamente un rol fundamental en la lucha por el poder.

ML: Recuerdo de pronto la famosa fotografia de ias presas senderistas del penal de Canto Grande coreando las consignos maoistas, imagen que luego ustedes utilizan en Viva el maoismo, y que 
nos coioca nuevamente en los modos de organización corporai de la ideologia, lo distribución fisica del discurso a través del rito y la complexion del cuerpo. No podemos extraviar el hecho que la violencia aún no ha terminodo y que ese legado está inscrito aun en muestros cuerpos, y es necesario procesarlo. Por eso me parece importante la pregunta sobre el papel de la escritura y la visualidad en la construcción de memorias y representaciones que ponen en conflicto los modos consensuados de pensar lo guerra, pero también aquellas otras que desmantelan constantemente las ficriones de Estodo, la ficción de que vivimos en un pais democrático e igualitario donde toda disidencia es producto de una violencia irracional.

AM: Exacto Nos encontramos en una situación donde la política es ordenada por el Estado, y por ello cuando hablamos de arte hablamos de las posibilidades de agujerear ese territo. rio de una forma tan impredecible que realmente permita poner en entredicho su discurso y sus lineas de dominación. O incluso, abrir los diques de la liberación. No seráa algo permanente pero puede permitirnos cambiar de lugar, violentar las fantasias coloniales instaladas y mantener viva la posibilidad de imaginary poner en marcha otras tealidades. Eso es algo que yo redescubri mientras estaba en la cárcel al sentir como los talleres de arte permitian una liberación ética de una cantidad innumerable de personas. A través de la creación ellos pudieron volver a sentir su propia condición humana luego de haber sido oprimida. estrangulada, pisoteada, Nuevamente sentir que su existencia no dejaba de ser real en tanto podian seguif creando universos absolutamente nuevos y distintos. No importaba ya si les metieran mas barrotes o restricciones, ellos podian seguir siendo hombres. Quiza si los que nos asumimos creadores visuales fuéramos concientes de ello nuestros actos tendrían otras repercusiones. Esa posibilidad de la estética de construir otros imaginarios, o de inscribirse en el ya existente para imaginar otros origenes. Yo creo que en el fondo me hicieron un favor con esas vacaciones pagadas por el Estado. 